\title{
THE EFFECT OF FINANCIAL CAPITAL ON INNER-CITY STREET TRADING
}

\author{
Chris Callaghan* \\ University of the Witwatersrand \\ Chris.callaghan@wits.ac.za
}

June 2011

\begin{abstract}
This study extends and tests conceptions offered by the nutrition model of efficiency wage theory into the informal street-trading context. Three street-trader samples from 2008, 2009 and 2010 were drawn from the Johannesburg city centre. Statistical parametric and non-parametric analysis was used for a longitudinal investigation of certain associations of initial investment, or the money investments of street traders at start-up. Partial correlation analysis was used for further analysis of the 2010 sample. Findings suggest that policymaker interventions might best target traders earning under a threshold of earnings of about R230 per day. More specifically, training might offer such traders insight into how to change their product offerings to products associated with higher returns. Further, any interventions that might raise street-trader earnings above this threshold might enable such traders to obtain a positive return on capital invested in the sector.
\end{abstract}

Keywords

Informal sector; initial investment; street traders; earnings; satisfaction.

*Mr Chris Callaghan is a lecturer in the School of Economic and Business Sciences at the University of the Witwatersrand, South Africa. 


\section{INTRODUCTION}

Debates about the fundamental nature of the informal street-trading sector exist, according to which these traders are considered to be constrained within a context akin to a secondary labour market (Cassim, 1982), or to be within a context that can enable their development to more developed enterprises (De Soto, 1989). Central to this issue is the empirical investigation of the return to the different forms of capital. The more evidence that is found to support the presence of returns to capital, such as human capital (Becker, 1975), social capital (Coleman, 1988) and financial capital, the more this sector might be considered to be a developmental context.

The more this sector might be considered a developmental context wherein capital theory operates, or in other words, whereby a return on human, social and financial capital does exist, then policymakers and street traders might be able to have recourse to clear policies and measures to uplift individuals in this sector.

However, inasmuch as capital theory posits returns to accrue to investments across contexts, and the literature exists to support these claims, absent from the literature is a consideration of the associations of financial investment in the informal street-trading context. Despite descriptive research in the sector (ESSET, 2007; Mitullah, 2003; Tissington, 2009), specifically absent from the literature in this context are findings relating to the structural associations of financial investment. It is argued that an analysis of the effects of financial capital in this context could result in the identification of differences in the structure of capital returns in this sector. It is further argued that a structural dichotomy might exist in the structure of the interrelationships that make up the sector, with a coarse differentiation of the sector into a survivalist sub-sector and an entrepreneurial sub-sector.

Findings related to tests of capital theory in this context might have the potential to take the field of informal street-trader research in new directions more focused upon street-trader upliftment that are anchored in improving the returns to capital for these people. The assumption upon which this argument rests is that street trader outcomes are indeed the function of different forms of investment, be they investment in education, or learning (Becker, 1975), or some form of investment in social factors (Coleman, 1988), or financial investment itself. If capital theory that predicts returns on money invested in this sector is found to be supported, then this has practical importance. Policymakers would then have a clearer understanding of how to effect street-trader upliftment. The underpinnings of such an assumption need to be investigated. To know under what conditions capital has a relatively more significant return is also salient in this context.

Thus implications for theory and practice are expected to flow from such a testing of capital theory. Street-trader investment and returns are under-researched, and with the focus of development in South Africa currently, increased insight into the mechanisms of capital investment in the informal sector might offer further insight into street-trader upliftment.

\section{INITIAL INVESTMENT AND THE INFORMAL STREET-TRADING CONTEXT}

To the extent that earnings were found to be associated with initial investment, this might also indicate the extent of the contribution of initial investment to earnings. This might therefore also suggest the extent to which factors other than initial investment might be associated with 
earnings. In certain contexts initial investment differences have been found to equal out over time (Parker, 2000). Knowledge of the relationships between initial investment and earnings in this context might further suggest the extent to which this context does not effectively 'equal out' such advantages associated with initial investment over time. If the earnings of a street trader were determined only by initial investment, then there would also be little scope for development in this sector. To the extent that initial investment were to be the dominant cause of informal earnings, this would indicate that more financially advantaged individuals would earn more, and thus inequality would be perpetuated to the extent that initial investment were more dominant as a cause of earnings. The level of analysis is that of the individual, as the individual is, for all intents and purposes, the business itself, in a typical street-trading enterprise.

\subsection{The research questions}

The core research questions addressed in this study are therefore:

- What is the role of financial investment at start-up, or initial investment in terms of informal outcomes?

- What are the differences between the associations of initial investment according to individual demographic factors over time in this context?

The associations between initial investment and individual demographic factors may be expected to provide insight into the infrastructure of relationships that comprise this sector, along the dimension of initial investment. Tests of associations between initial investment and gross earnings and continuance satisfaction, or informal outcomes, are expected to provide an exploratory framework of the role of initial investment in facilitating some measure of extrinsic and intrinsic outcomes for informal street traders. This research therefore extends current research performed in this specific sector into an investigation of the effects of initial investment. More specifically, certain research conducted in the same population (ESSET, 2007; Tissington, 2009) is used as a basis to extend analysis into the financial investment structure of relationships of the sector. This paper therefore extends the analysis of the structure of the sector using an exploratory statistical correlational design. A rationale for the inclusion of variables on the basis of their influence, as suggested by the literature is provided as follows, as the tested relationships are considered. Hypotheses are also derived.

\subsection{The structure of initial capital constraints}

Initial capital constraints have been found to be associated with significantly reduced performance for entrepreneurs (see Van Praag, de Wit \& Bosma, 2005). Earnings, measured as gross earnings, are expected to be associated with initial investment if performance is associated with initial capital investments in most contexts. However, evidence that suggests that this relationship holds in other contexts might not predict the extent to which this relationship holds in this context. Choices relating to entrepreneurship are typically constrained by access to capital and liquidity (Evans \& Jovanovic, 1989), and this also potentially has an exclusionary effect across levels of enterprise development. Therefore to the extent that formal enterprise might be associated with entry barriers, there might also be entry barriers to 'higher levels' of enterprise within the informal sector.

It is another argument of this study that a return on capital and a return on human capital do exist in the informal sector and that research into the effects of financial capital in this context 
can provide understandings that might enable upliftment, or identify discriminatory factors or constraints to informal sector street-trading upliftment. Individuals who earn more have in certain contexts demonstrated productivity earnings in excess of the net increase in their earnings according to the tenets of efficiency wage theory (McConnel, Brue \& Macpherson, 2003). According to this theory, individuals with lower earnings can be less productive. If higher earnings for an individual can result in increases in productivity that exist net of the increase in earnings this can perhaps be taken to represent some degree of increased functionality. It could therefore be argued that in the informal inner city street-trading context at some point extremely low earnings might be associated with some element of this dysfunctionality. The nutrition model of efficiency wage theory posits that in extremely impoverished contexts, higher earnings that accrue to individuals might increase productivity to a greater extent than the net increase in these earnings due to better health and nutrition, for example (McConnel et al., 2003).

\subsubsection{A threshold of dysfunctionality}

If a threshold exists whereby expected relationships, or functional relationships, are found to no longer hold, then it is argued that some type of dysfunctionality threshold has been identified. It is argued that across the entire sample, initial investment will be expected to be associated with higher earnings. However, it is also argued that traders earning very low levels of earnings are associated with a degree of dysfunctionality, where below a certain level of earnings, returns to initial financial investment do not exist. This study seeks to identify but one measure of this potential dysfunctionality threshold: the threshold of earnings under which a return to initial financial investment is no longer functional.

\subsection{The hypotheses}

On the basis of the evidence from other contexts that suggests that lower endowments of initial investment represent a constraint to enterprise performance, the following hypothesis is derived:

\section{Hypothesis 1, that there is a significant association between initial investment and earnings.}

The associated falsifiable null-hypothesis is derived: Null-hypothesis 1: There is no significant association between initial investment and earnings. Initial investment is measured as the amount of money invested in the street-trading enterprise at start-up. Earnings are measured as gross earnings per day. No measure is made of net earnings. The association between initial investment and continuance satisfaction is considered as follows.

According to Lumpkin and Dess (1996) enterprise performance spans further than conceptions of financial performance, and can include satisfaction or other measures. If satisfaction represents some degree of intrinsic return on the various inputs associated with the streettrading process, according to Lumpkin and Dess (1996), then this is a dimension of streettrading outcomes that might be considered a measure of an intrinsic counterpart to the extrinsic measure of performance represented by gross earnings. To the extent that higher-order needs are facilitated by higher earnings, when lower-order needs are met (Maslow, 1988) higher levels of earnings which might be associated with higher levels of initial investment might be expected to be associated with higher levels of continuance satisfaction. On the basis of this argument, the following hypothesis is proposed: 
Hypothesis 2: Higher levels of initial investment are significantly associated with higher levels of continuance satisfaction.

Continuance satisfaction is measured as the satisfaction of a street trader with continuing in street trading. The potential association between human capital and initial investment is now discussed.

Initial investment or capital investment as a factor needs to be included in studies of street traders, lest the returns found on education or other factors are overstated (Smith \& Metzger, 1998). The inclusion of returns to capital is therefore important in an analysis of street-trader outcomes, and in terms of street-trader research, education and capital investment are typically included in analyses of outcomes. Therefore the capital variables human capital and social capital factors are also tested as to their relationships with initial investment. Human capital represents the return upon investment in the individual such as education and training (Becker, 1975). A common basis in human capital in the form of education is associated to some extent with an endowment of social capital, or the potential resources that accrue to an individual on the basis of membership of groups (Coleman, 1988). Therefore an individual with family support or the support of networks might have had a monetary advantage that enabled more years of schooling. This same underlying advantage might also have extended to a monetary advantage in terms of entry into the informal sector. To the extent that some degree of commonality between education and social capital is expected, according to Coleman's (1998) conception, hypothesis 3 is derived:

Hypothesis 3: Total education is significantly and positively associated with initial investment.

Human capital, or education, is associated with increased productivity (Becker, 1975), which is expected to facilitate the attainment of outcomes in different areas of activity. More educated individuals might therefore also be expected to be able to also access capital more easily to the extent that this was dependent upon skills learned in schooling. Whereas education is a factor endowment of the individual, other factors might be associated with initial investment that relate to the trading context. The operation of a rental stand might fundamentally be associated with a different experience of street trading. This factor is considered as follows.

Higher returns have been found to be associated with informal traders who could afford to stock more financially intensive goods, such as technologically oriented goods, although access to capital can remain a significant constraint in this regard (Teltscher, 1994). To the extent that certain goods associated with higher capital intensity might yield higher earnings, street-trader 'graduation' might follow a path of increasing the capital intensity of provision over time.

Higher levels of initial investment and a smaller size of enterprise might be more associated with the choice of an entrepreneur to continue in an entrepreneurial venture (Gimento, Folta, Cooper \& Woo, 1997). However, smaller enterprises might be more likely to fail than larger enterprises (Robb, 2002). In the Johannesburg inner-city street-trading sector, more specific constraints might exist with regard to enterprise size, and also with regard to the vulnerability of a street trader to stock confiscation (Tissington, 2009). According to Tissington (2009:51):

\footnotetext{
"[s]tartlingly, many traders said that the main reasoning behind their choice of goods to sell was to be able to run and hide quickly if the Metro police came ... and there is a sense that many traders have to limit the amount and value of their stock in order to be able to move quickly".
}

However, a lack of "access to capital was also repeatedly cited by traders as a barrier to growing and improving their businesses" (Tissington, 2009:51). A further challenge to capital accumulation is the need to pay for storage of stock, or its safekeeping if it cannot be carried 
home each day (Tissington, 2009). If it were possible for street traders to develop in this sector along a dimension of capital accumulation, this might be along the dimension of enterprise size, or along the dimension of capital accumulation. Enterprise size might therefore be fundamentally associated with the size of a trader's stock.

The size of a street trader's stall area is constrained by the City of Johannesburg Metropolitan Municipality by-laws (City of Johannesburg, 2004). A street trader must "ensure that his or her property area of activity does not cover an area of a public road or public space that is greater in extent than six square meters (with a maximum length of three meters) or unless otherwise approved by the Council" (City of Johannesburg, 2004:5). However, street traders might be able to grow their enterprise through operating more than one stand. Yet in order to do this successfully, the trader might have to reach a certain level of development in one enterprise. The operation of a Council rental stand might be a factor that enables the accumulation of capital in that such a rental stand would allow a trader to operate without stock confiscations.

However, it is difficult to ascertain whether the trading stand is directly rented by the individual or if he or she is leasing the stand from another person, because street traders report paying rental amounts that vary from R50 to R500, and to report paying daily, weekly, monthly and yearly (ESSET, 2007). If a secondary market in rental stand rentals were to exist, this might indicate that this dimension of capital development might be constrained in favour of those traders who have the financial resources to afford to pay for such a further investment.

To some extent, the cost of such a rental stand might therefore be a barrier to a street trader reaching a 'critical mass' of capital intensity. If the operation of a rental stand were associated with initial investment, then this would indicate that the informal sector might be used by individuals with more access to resources in a different manner than those with fewer resources. Not being able to afford a rental stand might constrain some traders to lower levels of earnings. Such a differentiation might further contribute to an earnings differentiation within the sector for some traders. Therefore, it is predicted that individuals with more money to invest in a street-trading enterprise would also be more likely to be able to afford a rental stand:

Hypothesis 4: The operation of a rental stand is positively and significantly associated with higher levels of initial investment.

If initial investment is associated with higher levels of earnings, this would indicate a return to capital invested on entry into the sector. However, a certain component of earnings is expected also to be associated with capital investments after entry into the sector. Capital accumulation after entry into the sector might be facilitated through a graduation in the sector to more capital-intensive product offerings. If this did indeed occur, and earnings became primarily associated with capital investments derived from earnings after entry, then it would be expected that over time differences in initial investment would be found to be insignificant (Parker, 2000). This would be a scenario associated with functionality: the functionality of capital investment post-entry.

However, $92 \%$ of inner-city Johannesburg street traders sampled in 2007 were found to have been selling the same product, with no changes in product category since start-up (ESSET, 2007). This might suggest that if significant constraints to capital development exist along this dimension and if certain product classes are relatively more capital-intensive and earn more than other classes, then an individual street trader's financial fortunes might be tied to some extent to his or her product category at start-up. If this were so, then the determinants of the financial structure of the sector might be disproportionately associated with relative financial 
advantages at start-up. To the extent that certain product classes might be associated with higher earnings, and that initial investment might be associated with the enablement of entry into one of these higher-earning product classes, it is proposed that:

Hypothesis 5: There is a significant association between certain product classes and initial investment.

Product classes were measured in the 2008 and the 2010 data only. The association between gender and initial investment is considered as follows.

Differences between informal sector outcomes or practices between female and male traders in this context might reflect gender differences inherent in the broader South African society, as South Africa has improved to sixth position worldwide on the Global Gender Gap Index (Hausmann, Tyson, \& Zahidi, 2009). Yet differences in enterprise gender-role orientation have been found, and certain enterprise effects have found to be associated with cultural factors that ascribe different enterprise roles or societal roles to the different genders (Mueller, 2008). Enterprises owned by women have been found, in certain contexts, to be associated with higher failure rates, according to Robb (2002). If gender discrimination did exist, or if safety concerns did exist in a way that constrained earnings by gender, then such differences might be found in this context.

In 2008 xenophobic riots occurred in many parts of South Africa (Russel, 2008), also affecting the Johannesburg city centre. To the extent that safety and security in the inner city might have a different influence upon the behaviour of female street traders, with regard to decisions about entering the sector, potential female entrants with access to more resources might prefer other context of enterprise. This might lead to more survivalist female entrants being present in the sample. Therefore the following hypothesis is proposed:

Hypothesis 6: There is a positive and significant association between gender and higher levels of initial investment.

The methodology applied in this research is now discussed.

\section{RESEARCH METHODOLOGY}

The research methodology is discussed according to the following structure. First, the design of the study is introduced. Then the sampling process is outlined. Following this the instrument is discussed. The section concludes with an explanation of the method of data analysis applied. The design of the study is considered as follows.

\subsection{The research design}

An exploratory correlational research design was applied. In cases where a correlation test could not be used, as in the case of a relationship between a binary variable and a continuous variable, the Kruskal-Wallis test was used. In this manner descriptive research around financial capital invested in the sector was extended into an exploratory investigation of associations of such capital. 


\subsection{The sampling process}

The population from which these samples were drawn was that of the Johannesburg inner-city street-trading population. The population was sampled separately in 2008, 2009 and 2010. In an attempt to differentiate the core inner city street-trading context from adjacent areas of a more residential, industrial or transport-oriented nature, the area was demarcated to be within the borders of Plein street to the north, End street to the east, Faraday street to the south and Sauer street to the west. A grid was developed of the approximately two hundred street blocks. Using random number tables, about $10 \%$ of the blocks were sampled, and the traders on these blocks were counted. This inner city street-trading population was estimated to be about 5000 traders. A sample size calculation was undertaken, which indicated that a sample of about 100 would be enough to pick up a R20 difference in gross earnings at the $10 \%$ level of significance. The standard deviation of the sample and not the population was used for this calculation.

A sample size of about 300 respondents was set as the approximate .target number of respondents in these three studies. Due to the ethical commitment to traders wishing to remain obscure, refusals were unconditionally respected. Claims are therefore made on the basis of convenience sampling.

In order to provide a longitudinal structure to the investigation, samples were taken in 2008 $(n=339), 2009(n=308)$ and $2010(n=302)$. The most current sample (2010) was earmarked for further analysis in the form of parametric partial correlation analysis. Therefore street traders selling services who reported starting with no initial investment were removed from the analysis, so that only retail traders were included. This was done in order not to confound the analysis, as service traders such as those undertaking hair braiding were found to be able to start their enterprises with little or no capital investment of the sort associated with retail traders. The results are therefore considered to be generalisable only to similar contexts and to traders who have invested monetarily in their enterprises. A research team administered the questionnaires according to a strict sampling protocol. The sampling protocol remained the same across the years. With an average turnover in the sector of between five and six years, it was expected that a significant portion of the traders sampled in each subsequent year were new to the sector. The ethical protocol followed ensured that traders were granted confidentiality and anonymity. Traders were assured that their names or their position on street sides were not to be recorded. The objective was to sample the population in each year, and no measure was included as to which traders were included across the years. Further insights might be provided by further research that includes such a measure.

\subsection{The sampling instrument}

The questionnaire or survey instrument included items that sampled information about gender, age, products sold, years in Johannesburg, city or town of origin, country of origin, hours worked per day, days worked per week, initial capital investment, years of formal education, tertiary education, years of trading in the sector, gross earnings per day and satisfaction with continuing in street trading. The latter variable was measured in the form of five-point Likert scales. Three items were placed within the instrument with one reversed: "I am happy with continuing in street training" and "I am not happy with continuing in street trading" were used as the positive and negative poles, respectively. The wording of the items differed very slightly, as the scale needed to remain as simple as possible. The Cronbach's Alpha value for the items was .938. Further, an exploratory factor analysis was performed. The assumptions associated 
with the use of exploratory factor analysis were checked. The Kaiser-Meyer-Olkin test value was .66 , which was above the required value of .5. Bartlett's test for sphericity was found to be significant, with a chi-square value of 1148.1. On the basis of these tests the sampling adequacy required by the factor analysis was considered to be acceptable. The factor structure of the 2010 data is reported in TABLE 1, below. The three continuance satisfaction items dominate factor one, with loadings of .879; .907; and .936. Factor two is dominated by a contrast of initial investment, total education and earnings with years in Johannesburg and experience. Factor three is dominated by hours and days worked, which might indicate a dimension of work ethic in the sector. Factor four is dominated by years in Johannesburg, initial investment (with the higher factor loading), experience and earnings per day. The factor structure indicates that initial investment is a significant component of the structure of relationships in this informal streettrading context.

TABLE 1: The Factor Structure: 2010 Component Matrix

\begin{tabular}{lcccc}
\hline & \multicolumn{4}{c}{ Component } \\
& 1 & 2 & 3 & 4 \\
\hline Yearsinhhb & .281 & -.753 & -.002 & .402 \\
HoursWorkedPDay & .086 & -.049 & .768 & -.104 \\
DaysWorkedpWeek & .118 & .128 & .755 & -.269 \\
Initiallnvestment & .145 & .473 & .147 & .602 \\
TotalEducation & -.207 & .573 & -.076 & .287 \\
Experience & .389 & -.693 & .153 & .375 \\
ContSat1 & .879 & .171 & -.141 & -.145 \\
ContSat2 & .907 & .142 & -.084 & -.173 \\
ContSat3 & .936 & .137 & -.117 & -.143 \\
Earningspday & .303 & .374 & .191 & .568 \\
\hline
\end{tabular}

Source: Author's analysis

\subsubsection{Extraction method: Principal Component Analysis}

The purpose of the surveys was primarily to obtain information about the structure of relationships around earnings in the sector. The objective of the 2010 survey, however, was to obtain further information that included information about product sales. Product sales information was also sampled in 2008 and yet not in 2009. The 2010 survey was planned to be the basis for a deeper analysis of the structure of relationships in the sector. In the 2010 survey dummy variables were therefore again created for certain product categories, including clothes, fruit and vegetables, technologically related goods, and food. The 2010 data revealed the inclusion of eight traders offering services and not goods. These were removed from the sample, and 295 respondents remained within the sample. These outliers were removed due to the use of parametric partial correlation analysis for the 2010 data. TABLE 2 reports the variable means for the 2008, 2009 and 2010 data. The instrument was administered across the years in the same form, except for certain differences reported in TABLE 2.

The interviews were allocated approximately 20 minutes each. Administrators did not interrupt traders who were engaged in sales. If a potential customer approached, then the administrator would wait until the interaction between the trader and the customer was concluded before 
proceeding. The frequencies are reported within the same table for variables that are binary in nature.

\subsubsection{The process of data analysis}

Pearson's correlation testing was undertaken. However, due to the potential vulnerability of Pearson's test to outliers, Spearman's rho measures were also used. Hypotheses 4, 5 and 6 were tested using Kruskal-Wallis tests. Cronbach alpha tests were undertaken on survey items such as continuance satisfaction. Continuance satisfaction was sampled using Likert-type scales. Three items were used.

With regard to hypotheses one and two, further parametric testing of the 2010 data was undertaken using partial correlation analysis in order to control for the influence of certain variables upon the zero order correlation between initial investment and each of the variables earnings and continuance satisfaction. The following variables are controlled: earnings $(\varepsilon)$ in the case of hypothesis two; continuance satisfaction (CS) in the case of hypothesis one; years in Johannesburg (YJ); Johannesburg origin (J0); hours worked per day (HW); days worked per week $(D W)$; total education (ED); tertiary education $(T \varepsilon)$; rental stand operation (RS); experience $(\varepsilon X)$ or years spent in the sector; and gender $(G)$. The letters in brackets after each variable indicate its abbreviation. In TABLES $\mathbf{4}$ and $\mathbf{6}$ the results of this testing are shown, with each variable indicated by its abbreviation.

In TABLE 3, the Pearson's and the Spearman's correlation coefficients for associations with initial investment are shown. TABLE 7 indicates the final results of the hypothesis testing process. The research findings are reported and discussed as follows.

TABLE 2: Comparative descriptive statistics: means and frequencies

\begin{tabular}{|c|c|c|c|}
\hline Variables & 2008 & 2009 & 2010 \\
\hline Gender* (Male) & $57 \%$ & $67 \%$ & $62 \%$ \\
\hline Years in Johannesburg & 9.7 & 9.3 & 10.7 \\
\hline Johannesburg origin* & $12 \%$ & $14 \%$ & $8 \%$ \\
\hline Hours worked per day & 10.2 & 10.5 & 10.7 \\
\hline Days worked per week & 6.19 & 6.36 & 6.4 \\
\hline Initial Investment** & R428 & R398 & $\mathrm{R} 1181 * \star \star$ \\
\hline Tertiary & $12 \%$ & $10 \%$ & $15 \%$ \\
\hline Total years of Education & - & 10.17 & 9.90 \\
\hline Experience** (years) & 4.23 & 5.90 & 6.40 \\
\hline Rental stand & $41 \%$ & $47 \%$ & $41 \%$ \\
\hline Continuance satisfaction & $4.28 \star \star \star$ & 8.97 & 6.80 \\
\hline Earnings per day $\star \star$ & Rl61 & $\mathrm{R} 262$ & 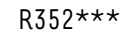 \\
\hline
\end{tabular}

\section{Source: Author's analysis}

Notes: reported values are for means unless the variable is indicated as a binary variable. In the case of binary variables the frequencies are reported as a percentage. * indicates binary variable** indicates upper limit to measure $\star \star \star$ indicates different upper limit to measure therefore not directly comparable to other data sets 


\section{RESULTS AND DISCUSSION}

In 2008 the mean level of initial investment in a street-trader enterprise was found to be approximately R427,58 (standard deviation 298.5); in 2009 it was about R398,21 (standard deviation 313.5). However, in these years the measure did not sample initial investments above about R1 750, in order to offer a range of earnings that excluded significant outliers. Therefore these are not true measures of the means. In 2010 the measure of initial investment was extended to capture responses ranging up to R4 850 . This extension reflected a higher mean: Rl 181,49, with a standard deviation of R1 286,54. The median initial investment in 2008 is about $\mathrm{R} 600$; in 2009 is about R500; and in 2010 is about R650. This reflects the pattern of the means data: that initial investment dropped off in 2009. The 2008 survey was administered a month before the xenophobic events of that year (Russel, 2008) within the inner city. A specific analysis of the potential effects of the xenophobic events of 2008 is beyond the scope of this study. However, the data indicates that whereas traders of foreign origin typically earned more than those of local origin in 2008 and 2010, in 2009 the relationship is reversed. In 2009 traders of local origin were found to earn more than traders of foreign origin. A possible explanation of the lower median investment of 2009 is that traders of foreign origin with relatively higher levels of investments in the sector might have left the sector over the 2009 period following the xenophobic events.

Therefore, if the xenophobic events of 2008 were to have had a temporary influence on initial investment then such a result might be expected. An alternative explanation might be that relatively more local traders with higher levels of initial investment may have temporarily entered the sector at this time. However, by 2010 the trend seems to have stabilised. According to the median data, the increase in initial investment over this period is about $8.3 \%$, or an annualised increase of about $2.8 \%$ per year. Further research into initial investment adjusted for inflation is suggested in this context. A potential limitation of this study is that initial investment reports are not adjusted for inflationary effects. However, it is argued that the methodology of this study is appropriate for its primary purpose: an initial exploratory investigation into the associations of initial investment in this specific context, which necessitates the use of broad measures, and a delimitation of the scope to a broad, yet relatively less deep analysis. Further research is suggested into the exit paths of street traders. Such research might build upon exploratory studies such as these, and provide more insight into the reasons for such exit. Such research might address the limitations inherent in quantitative exploratory research and provide causal insight into why changes in the structure of the sector occur. The results of the statistical testing are considered as follows, according to the tested null-hypotheses that correspond to each hypothesis derived above.

Null-hypothesis 1: There is no significant association between initial investment and earnings. Gross earnings and initial investment were found to be positively and significantly correlated according to Pearson's measure, and also according to Spearman's measure across the 2008, 2009 and 2010 samples (TABLE 3). A parametric analysis of the partial correlations of the 2010 data indicates (TABLE 4) that the zero order association between initial investment and earnings is not significantly influenced after controlling for each the control variables. 
TABLE 3: Pearson and Spearman coefficients of correlations for 2008, 2009 and 2010

\begin{tabular}{|c|c|c|c|c|c|c|}
\hline \multirow{2}{*}{ Variables } & \multicolumn{3}{|c|}{ Pearson } & \multicolumn{3}{|c|}{ Spearman } \\
\hline & 2008 & 2009 & 2010 & 2008 & 2009 & 2010 \\
\hline Initial Investment with: & & & & & & \\
\hline 1. Earnings & $0.293 * \star$ & $0.323 * \star$ & $0.327 * \star$ & $0.325 * \star$ & $0.345 * \star$ & $0.400 * \star$ \\
\hline 2. Continuance satisfaction & & & & & & \\
\hline 3. Total Education & $0.262 \star \star$ & $0.134 \star$ & $0.228 * \star$ & $0.213 * \star$ & $0.203 * \star$ & $0.198 * \star$ \\
\hline 4. Years in Johannesburg & & & & $0.158 * \star$ & & \\
\hline 5. Experience & & & & & $0.238 *$ & \\
\hline 6. Days worked per week & $0.143 *$ & & & $0.113 *$ & & \\
\hline 7. Hours worked per day & & & & $0.192 * \star$ & & \\
\hline
\end{tabular}

Source: Author's analysis

Notes: $n=339 ; 2009 n=308$; and $2010 n=295$. Significance: $p<.10^{\wedge} ; p<.05^{\star} ; p<.01^{\star \star} p<.001^{\star \star \star}$

According to the Pearson correlation measure, about $10.67 \%$ of the variance is shared between earnings and initial investment. This indicates that to the extent that these variables are correlated, advantages of individuals entering the sector are maintained, and such advantages seem to be perpetuated. However, on a more positive note, these findings indicate that most of the variance associated with earnings is not explained by initial investment, and this might indicate that other factors are having an influence upon earnings in this context. This suggests that it is possible for street-trader earnings upliftment to occur beyond the influence of initial investment. If street traders are able to better their conditions, researchers and practitioners need to be able to identify plausible mechanisms for earnings improvement. If the sector is to be used as a training ground for entrepreneurship (De Soto, 1989) and enterprise development, traders might need to graduate between product categories to achieve this, as certain categories were found in the most current inner-city data (2010) to be associated with higher earnings, such as footwear and clothing.

TABLE 4: Partial correlations between initial investment and earnings with variables controlled for

\begin{tabular}{|c|c|c|c|c|c|c|c|c|c|c|}
\hline Controlled: & $C S$ & yJ & 10 & $H W$ & $D W$ & $\varepsilon D$ & $T \varepsilon$ & $R S$ & $E X$ & G \\
\hline Initial & $0.311 *$ & $0.326 *$ & $0.317^{\star}$ & $0.320 *$ & $0.318 *$ & $0.299 *$ & $0.309 *$ & $0.312^{\star}$ & $0.323 *$ & $0.299 *$ \\
\hline \multicolumn{11}{|l|}{$\begin{array}{l}\text { Investment } \\
\text { with } \\
\text { earnings }\end{array}$} \\
\hline Zero order co & cient o & rrelati & betwee & itial in & tment & dearni & s: 0.328 & $<.000$ & & \\
\hline
\end{tabular}

Source: Author's analysis

Significance: $p<.001^{*}$

The accumulation of capital is a primary constraint to enterprise development (Van Praag et al., 2005), and these findings indicate that this is a significant constraint in this sector. This mechanism, however, seems to be underutilised, as $92 \%$ of traders in this context have reported not ever changing their product offering since entering the sector (ESSET, 2007). In this context street traders who have invested more at start-up have been found to be more innovative, or to report changing their product provision profile more often (Callaghan and Venter, 2011). 
TABLE 5: Earnings: Pearson and Spearman coefficients of correlations

\begin{tabular}{|c|c|c|c|c|c|c|}
\hline \multirow{2}{*}{ Variables } & \multicolumn{3}{|c|}{ Pearson } & \multicolumn{3}{|c|}{ Spearman } \\
\hline & 2008 & 2009 & 2010 & 2008 & 2009 & 2010 \\
\hline Earnings with: & & & & & & \\
\hline Age & & $0.149 \star \star$ & & & $0.174 \star \star$ & \\
\hline Years in Johannesburg & & $0.174 \star \star$ & & & $0.227 * \star$ & \\
\hline Hours worked per day & $0.147 \star \star$ & $0.178 * \star$ & & $0.149 \star \star$ & $0.219 \star \star$ & $0.101^{\wedge}$ \\
\hline Days worked per week & & $0.237 \star \star$ & & $0.101^{\wedge}$ & $0.224 \star \star$ & \\
\hline Initial investment & $0.293 * \star$ & $0.323 * \star$ & $0.319 * \star$ & $0.325 * \star$ & $0.345 \star \star$ & $0.379 * *$ \\
\hline Total education & $0.123 \star$ & & $0.139 *$ & $0.117 \star$ & & $0.168 * \star$ \\
\hline Experience & & $0.153 * \star$ & & $0.159 * \star$ & $0.238 * \star$ & $0.109^{\wedge}$ \\
\hline Continuance satisfaction & $0.213 \star \star$ & $0.233 \star \star$ & $0.203 * \star \star$ & $0.212 \star \star$ & $0.247 \star \star$ & $0.225 \star \star$ \\
\hline
\end{tabular}

Source: Author's analysis

Significance: $p<.10^{\wedge} ; p<.05^{\star} ; p<.01^{\star \star} p<.001^{\star \star *}$

Of concern, however, is that product choice is primarily made on the basis of a quick 'escape' from authorities and stock seizure (Tissington, 2009). When the associations between initial investment and earnings by earnings deciles are tested, initial investment begins to be statistically associated with earnings only at decile six. Decile seven also reflects this significant association. However, deciles eight, nine and ten also fail to reflect a significant association between these variables. Traders falling into decile six $(n=30)$, below which no significant association is found between initial investment and earnings, have a mean of Rl 343 for initial investment and a mean of R273 for earnings, with a range of earnings between R230 and R310. Traders earning less than about R230 per day in gross earnings are therefore found to have no net per decile significant association between earnings and initial investment. This finding might indicate that the effect of initial investment may be enabled by another or other factors associated with higher earnings. To the extent that traders earning less than this might be faced with a constraint that might act with regard to earnings and also the returns to initial investment, this constraint might present itself as a dysfunctionality threshold, above which earnings and its relationship with capital returns are less dysfunctional. FIGURE $\mathbf{l}$ illustrates the means of initial investment and earnings per decile.

In terms of a long-term trend, the Spearman and Pearson coefficients for the association between earnings and initial investment (TABLE 3 ) show an increasing trend of association over the years 2008, 2009 and 2010. This might indicate that the returns to capital investment on entry into the sector are increasing over time, notwithstanding the inflationary effects of initial investment. However, if certain traders are found to be effectively 'trapped' in a band of earnings below such a potential 'dysfunctionality threshold', such increases in earnings associated with capital investments might not exist for these individuals.

Despite not being able to draw out the specific causes of this potential dysfunctionality along the dimension of the operation of financial capital below this threshold, these findings are considered to support the arguments of efficiency wage theory and the nutrition model in terms of their prediction: that lower levels of earnings can be associated with lower net levels of productivity, a state of relative productivity dysfunctionality (McConnel, et al., 2003). 


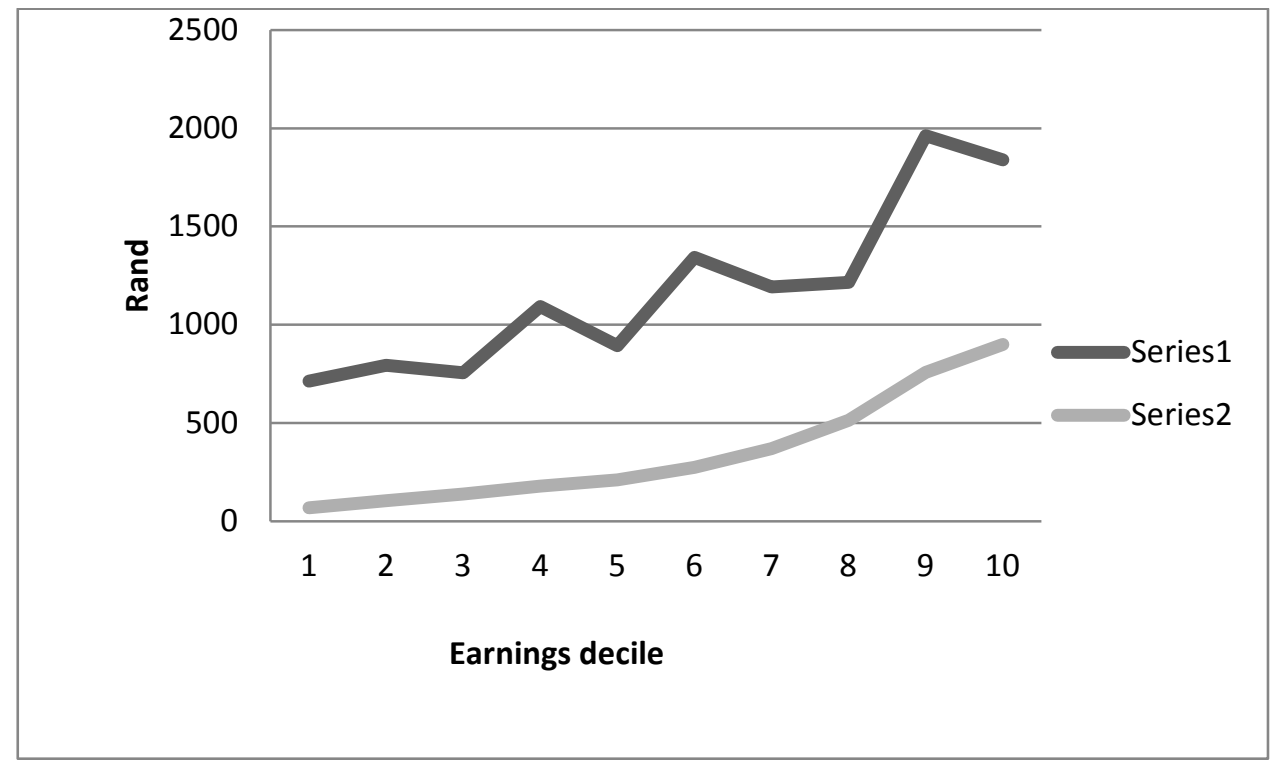

\section{FIGURE 1: Means of Initial Investment (series 1) and Earnings per day (series 2) per earnings decile}

\section{Source: Author's own analysis}

Further research into how capital accumulation can be facilitated in this sector is recommended. It is argued that above a certain threshold of earnings, a virtuous circle of effects might be set in motion and that below this threshold a vicious circle of capital constraint might exist. The findings indicate that earnings are associated with initial investment and that earnings are also associated with more capital-intensive product offerings, and so if policymakers were able to provide support in terms of capital investment, or if they were able to provide rental stands or more training, street trader upliftment might be enabled. The nullhypothesis is rejected, and the alternative hypothesis is accepted.

\section{TABLE 6: Partial correlations between initial investment and continuance satisfaction with variables controlled for}

\begin{tabular}{|c|c|c|c|c|c|c|c|c|c|c|}
\hline Controlled: & $C S$ & yJ & 10 & $H W$ & $D W$ & $\varepsilon D$ & $T \varepsilon$ & $R S$ & $\varepsilon X$ & $G$ \\
\hline Initial & 0.015 & $0.106^{\wedge}$ & 0.080 & 0.079 & 0.077 & $0.111^{\wedge}$ & 0.077 & 0.059 & 0.092 & 0.085 \\
\hline \multicolumn{11}{|l|}{$\begin{array}{l}\text { Investment } \\
\text { with } \\
\text { earnings }\end{array}$} \\
\hline Zero order co & cient & rrelati & betwe & itial i & tment & conti & ances & factio & .079 & 168) \\
\hline
\end{tabular}

Source: Author's analysis

Notes: Results are for year 2010. Significance: $p<.10^{\wedge} ; p<.05^{\star} ; p<.01^{\star \star} p<.001^{\star \star \star}$

Null-hypothesis 2: There is no significant association between initial investment and continuance satisfaction. No significant association was found between initial investment and continuance satisfaction (TABLE 3 ). This might indicate intrinsic street-trading outputs in this sector, to the extent that a measured dimension of these in the form of continuance satisfaction might not be related to extrinsic inputs. Satisfaction is, however, found to be 
positively associated with earnings (TABLE 5) for the inner-city 2008, 2009 and 2010 samples, yet only earnings is found to be associated with initial investment. However, in the parametric testing of the partial correlations, when total education is controlled for (TABLE 6), the association between initial investment and continuance satisfaction is found to be positive and significant $(p<.054)$, on the border of the $5 \%$ level of significance with a coefficient of .111. This might indicate that individuals who invest more in their enterprises might experience the sector in such a way as to be relatively less dissatisfied than traders with fewer resources invested at entry, holding constant education. If this were so, then traders with fewer resources to invest in the sector might be more dissatisfied with continuing in trading.

When years in Johannesburg are controlled for, the same association is significant at just below the $10 \%$ level of significance $(p<.083)$ with a coefficient of .106 . If this finding were taken to be significant, this might reinforce the notion that, holding the years spent in the city constant, individuals who invest more at start-up are relatively more satisfied with continuing in trading.

However, these parametric findings should be treated with caution, as outliers have not been removed from the sample, and the non-parametric measure indicates no bivariate association to be significant between these variables. Further, the partial correlation analysis findings fail to attain significance at the $5 \%$ level, and the definitive indication either side of the potential presence of Type I or Type II errors is not excluded. Therefore claims are not made on the basis of these findings.

A more conservative claim is therefore made: that pending further evidence, people who invest more at start-up are not found to be significantly more satisfied with continuing in street trading. The null-hypothesis is supported and the alternative hypothesis is rejected.

Null-hypothesis 3: There is no significant association between initial investment and total education. Total education is found to be significantly and positively associated with initial investment, according to both correlation measures for the 2008, 2009 and 2010 inner-city samples. This indicates that some common order effect might be associated with education, or human capital (Becker, 1975) might also be associated with social capital (Coleman, 1988). This supports the notion that higher levels of access to resources might increase an individual's access to more years of education and also higher levels of investment in the sector at start-up. Alternatively this might indicate that the higher levels of education representing human capital might be associated with more productive processes with regard to obtaining such capital. The long-term trend, however, according to the Spearman coefficients (TABLE 3 ), seems to indicate a movement toward a smaller association over time. The null-hypothesis is rejected and the alternative hypothesis is accepted.

Null-hypothesis 4: There is no significant difference in initial investment by rental stand operation. In the $2008(p<.0001), 2009(p<.0001)$ and $2010(p<.0002)$ data there is a significant difference in initial investment on the basis of rental stand operation according to Kruskal-Wallis tests. The null-hypothesis is rejected. This finding indicates that having more resources on entry into the sector is associated with the operation of a rental stand. To the extent that the operation of a rental stand might shield street traders from by-law contravention and from stock confiscations (ESSET, 2007; Tissington, 2009), those with more initial investment might have an advantage.

This advantage might not be available to other street traders due to potential constraints to obtaining such a stand, so this might be a mechanism whereby an initial advantage is perpetuated. Operation of a rental stand is significantly associated with differences in earnings 
only in the 2009 sample $(p<.0001)$ according to the Kruskal-Wallis measure. Operating a rental stand is also significantly associated with continuance satisfaction for the 2009 sample (at just within the $10 \%$ level of significance) and for the 2010 sample (at just outside the $5 \%$ level of significance) according to the Kruskal-Wallis tests. If traders are unable to afford a rental stand, they might be vulnerable to by-law infringement or stock confiscation. This finding supports the notion that traders without rental stands are more dissatisfied with continuing in street trading. This finding therefore indicates a further dimension along which the relatively more impoverished street trader is constrained. More impoverished traders might not have the same opportunities to advance, or to graduate to more capital-intensive product categories in the same manner as traders with better access to financial resources.

Policymakers might be able to facilitate the advancement and development of street traders by offering more access to legal rental stands. It is recommended that further research be undertaken into the potential dichotomy that might exist in the sector between those traders who are perhaps able to spend their way to legality, and those who are simply perhaps unable to obtain such legality due to financial disadvantage.

Null-hypothesis 5: There is no significant difference in initial investment by product class. In the analysis of the 2010 data, the Kruskal-Wallis measures found higher levels of initial investment to be associated with traders reporting product sales categories of clothes $(p<.0275)$ and footwear $(p<.0229)$. The other product categories tested from the 2010 data - food and technologically related products - reflected no significant difference in initial investment. The Kruskal-Wallis tests of the 2008 data indicated that clothing sales $(p<.0001)$ were associated with higher levels of initial investment. The categories included in the 2008 data were food, technological goods, clothing and a category for other items. In the 2008 data initial investment was found to differ by both food and technological goods, yet at just beyond the $5 \%$ level of significance for both of these categories. The null-hypothesis is rejected. Significant positive differences in earnings were found for clothes and footwear as product classes according to the Kruskal-Wallis tests. In the 2008 data clothing $(p<.0001)$, yet not food or technological goods, was found to be significantly associated with the operation of a rental stand according to the Kendal Tau test measure. However, clothing but not footwear was found to be significantly associated with the operation of a rental stand.

The finding that different product classes are associated with higher levels of initial investment (and earnings) indicates that a graduated increase in performance in the informal streettrading sector might be possible if traders were able to change their product offerings to categories with higher returns. However, such a change to more productive categories might be constrained by a lack of financial capital.

This suggests that inequality is present in this sector if financial advantages at start-up are perpetuated in a way that other traders might not be able to emulate. If $92 \%$ of street traders in this sector have reported not ever changing their product category offering since entering the sector (ESSET, 2007), this would indicate that few are using changes in product offerings as a form of accessing the potentially higher returns to investment of more capital-intensive categories.

Null-hypothesis 6: There is no significant difference in initial investment by gender. In the 2008 $(p<.001), 2009(p<.001)$ and $2010(p<.005)$ data, according to the Kruskal-Wallis tests, being male is found to be positively and significantly associated with higher levels of initial investment. The null-hypothesis is rejected and the alternative hypothesis is accepted. This finding confirms findings of case study research in Kenya, Cote D'Ivoire, Ghana, Zimbabwe, 
Uganda and South Africa that male street traders invest in more capital-intensive businesses and therefore achieve higher levels of profitability than female traders (Mitullah, 2003).

This finding suggests that perhaps fewer potential female entrants with higher levels of monetary resources are choosing to enter the sector, or, conversely, that male entrants with more resources might be more likely to enter. This might also indicate that relatively more females without resources might be entering the sector due to having less choice. The xenophobic violence of 2008 (Russel, 2008) might have contributed to security concerns on the part of female street traders. This might have increased the relative attractiveness of other avenues of investment for female traders. On the other hand, certain groups of traders of foreign origin are almost exclusively male (ESSET, 2007), and these traders might be bringing more initial investment into the sector.

Further research into challenges faced by female street traders is recommended. To the extent that a main source of harassment in this sector is "other traders, resulting from clashes over 'hijacking' of each other's business" (ESSET, 2007:4) being male might be a physical advantage. If so then this context might be gender-discriminatory, and further research might offer more insight into these effects. The 2010 data indicates that males are younger, with a mean of 31 years versus that of about 39 years for female traders. Females make up about $38 \%$ of the sample, with males making up about $62 \%$. About $55 \%$ of female traders are of South African origin and about $7 \%$ are of Johannesburg origin, whereas about $33 \%$ of males are of South African origin, and about $9 \%$ are of Johannesburg origin. This might indicate that more female migrants of South African origin may be trading in the sector, yet that more males of foreign origin trade in the sector, as male traders of foreign origin comprise about $41 \%$ of the entire sample, and female traders of foreign origin about $17 \%$ of the sample. Conclusions are presented and recommendations for further research are made as follows.

\section{TABLE 7: The results of the testing of the null-hypotheses}

\begin{tabular}{l|l}
\hline $\begin{array}{l}\text { Null-hypothesis 1: There is no significant association between } \\
\text { initial investment and earnings. }\end{array}$ & Null-hypothesis rejected \\
$\begin{array}{l}\text { Null-hypothesis 2: There is no significant association between } \\
\text { initial investment and continuance satisfaction }\end{array}$ & Null-hypothesis accepted \\
$\begin{array}{l}\text { Null-hypothesis 3: There is no significant association between } \\
\text { initial investment and total education }\end{array}$ & Null-hypothesis rejected \\
$\begin{array}{l}\text { Null-hypothesis 4: There is no significant difference in initial } \\
\text { investment by rental stand operation. }\end{array}$ & Null-hypothesis rejected \\
$\begin{array}{l}\text { Null-hypothesis 5: There is no significant difference in initial } \\
\text { investment by product class }\end{array}$ & Null-hypothesis rejected \\
$\begin{array}{l}\text { Null-hypothesis 6: There is no significant difference in initial } \\
\text { investment bygender }\end{array}$ & Null-hypothesis rejected
\end{tabular}

Source: Author's analysis

\section{CONCLUSION AND RECOMMENDATIONS}

This research extended current research in this specific sector (Callaghan \& Venter, 2011; ESSET, 2007; Tissington, 2009) into a further statistical analysis of the relationships around initial capital investment and its relationship to street-trader earnings. This research therefore 
addressed a gap in the literature relating to the effects of initial financial investment in the sector. In this manner this exploratory study is expected to provide a base from which researchers might further investigate the structure of financial effects in the sector. It is concluded that initial investment is significantly associated with earnings across all the samples. Product categories with lower capital intensity were found to be associated with lower earnings. To the extent that initial investment after time in the sector was still found to account for a significant association with earnings, the accumulation of capital after entry is found to be a primary constraint to enterprise development in the informal sector. Constraints to capital development found in the sector reflect those in other contexts (Van Praag et al., 2005).

Different product classes were, however, found to be associated with higher earnings. These product classes were also found to be associated with higher levels of initial investment. Street traders were found to be able to earn more if they move into more capital-intensive product classes. This mechanism, however, seems to be underutilised, as $92 \%$ of traders in this context have reported not ever changing their product offering since entering the sector (ESSET, 2007).

If product choice is primarily made on the basis of a quick 'escape' from authorities and stock seizure (Tissington, 2009), then not having the financial capital, or not having the earnings level within the sector to invest in a rental stand, or to graduate to another product category, might trap traders in a 'zone of dysfunctionality', or under a 'dysfunctionality threshold', under which significant returns to initial investment might not exist.

For deciles of earnings, the significance of the association between initial investment and earnings is found to be insignificant for traders earning below about R230. Below this level, initial investment is therefore not found to have a significant return. If the sector is to be used as a training ground for entrepreneurship (De Soto, 1989), it is concluded that policymakers and further researchers should focus upon the factors that constrain functionality in this context, so as to enable those at lower levels of earnings to experience the returns to financial capital invested and perhaps other outputs that are typically experienced by traders who earn more.

The predictions of efficiency wage theory and more specifically the nutrition model of efficiency wage theory seem to be supported, in that the nutrition model of efficiency wage theory posits that in extremely impoverished contexts, higher earnings that accrue to individuals might increase productivity to a greater extent than the net increase in these earnings (McConnel et al., 2003) due to improved nutrition, health and other effects. It is concluded that if traders were able to earn above this 'dysfunctionality threshold' then they might be able to obtain a significant return upon their financial investment in the sector.

Continuance satisfaction is not found to be associated with initial investment. It is concluded that there might be no specific direct intrinsic return associated with capital invested in streettrader start-up.

Total education is found to be associated with initial investment. It is concluded that the same factors that might have enabled access to resources or the support needed to complete more years of education might also support access to more resources for investment in this context. Alternatively, higher human capital endowments (Becker, 1975) in terms of learned personal productivity or skills might enable more educated individuals to obtain more resources or financing for investment into the sector.

Rental stands were found to be significantly associated with higher levels of initial investment, as were certain product classes such as footwear and clothing sales. 
It is recommended that further research be undertaken into the factors identified in this research as constraining functionality in this sector: into how learning in this sector might enable traders to move between product categories and graduate within, and also eventually out of, this sector; into how compliance with by-laws might be facilitated and fines and stock confiscations avoided and capital accumulation thus enabled; and into the effects of extreme poverty, whereby certain street traders find it impossible to accumulate capital in this sector.

Investments made by policymakers might enable certain of these traders to grow and formalise their enterprises, which might enable these traders to become taxpayers. Further research might indicate the returns to such interventions in real terms.

On the whole, policymakers can, on the basis of these findings, enable capital formation for these traders through increased training provision, and increased access to trading stands within the flows of city customers or through any measures that improve the nutrition and health of these individuals (McConnel, et al., 2003). It is therefore recommended that policymakers make a targeted effort to assist traders at the bottom strata of the sector, whether in city contexts or in township contexts, as such assistance might fundamentally alter the nature of street trading for these traders.

\section{LIST OF REFERENCES}

Becker, G.S. (1975). Human Capital, $2^{\text {nd }}$ edition. Chicago: University of Chicago Press.

Bird, B.J. (1988). Implementing entrepreneurial ideas: the case for intention. Academy of Management. The Academy of Management Review, 13(3), pp. 442-453.

Callaghan, C.W. \& Venter, R. (2011). An investigation of the entrepreneurial orientation, context and entrepreneurial performance of inner-city Johannesburg street traders. Southern African Business Review, 15(1), pp. 28-48.

Cassim, F. (1982). Labour market segmentation: the theoretical case. The South African Journal of Economics, 50(4), pp. 240-247

Churchill, N.C. \& Lewis, V.L. (1983). The five stages of small business growth. Harvard Business Review, 61, pp. 30-50.

City of Johannesburg. (2004). Street trading by-laws. [On-line] Available: http://www.joburgarchive.co.za/bylaws/streettrading_by-laws.pdf. (Accessed 11 January 2011)

Coleman, J.S. (1988). Social capital in the creation of human capital. American Journal of Sociology, 94, pp. S95-S120.

De Soto, H. (1989). The Other Path. New York: Harper \& Row.

ESSET. (2007). Street Traders Survey. Ecumenical Service for Socio-Economic Transformation. [0nline] Available: http://www.esset.org.za/PDF\%20files/Street\%20Traders\%20Survey\%20report.pdf. (Accessed 11 January 2011)

Evans, D.S. \& Jovanovic, B. (1989). An estimated model of entrepreneurial choice under liquidity constraints. The Journal of Political Economy, 97(4), pp. 808-827.

Gimento, J., Folta, T.B., Cooper, A.C. \& Woo, C.Y. (1997). Survival of the fittest? Entrepreneurial human capital and the persistence of underperforming firms. Administrative Science Quarterly, 42 (4), pp. 750-783. 
Hausmann, R., Tyson, L.D., \& Zahidi, S. (2009). The Global Gender Gap Report: World Economic Forum. [On-line] Available: http://www.weforum.org/pdf/gendergap/report2009.pdf. (Accessed 19 August 2010)

Lumpkin, G.T. \& Dess, G.G. (1996). Clarifying the entrepreneurial orientation construct and linking it to performance. Academy of Management Review, 21(1), pp. 135-173.

Maslow, A.H. (1987). Motivation and Personality, $3^{\text {td }}$ edition. New York: Harper \& Row.

McConnel, C.R., Brue, S.L., \& Macpherson, D.A. (2003). Contemporary Labor Economics, $6^{\text {th }}$ edition. Boston: McGraw Hill.

Mitullah, W.V. (2003). Street vending in African cities: a synthesis of empirical findings from Kenya, Cote D'Ivoire, Ghana, Zimbabwe, Uganda and South Africa. [On-line] Available:

http://wiego.org/publications/street-vending-african-cities-synthesis-empirical-findings-kenyacote-d039ivoire-ghana-. (Accessed 2 August 2011)

Mueller, S.L. (2008). Gender-role orientation as a determinant of entrepreneurial efficacy. Journal of Developmental Entrepreneurship, 13(1), pp. 3-20.

Parker, S.C. (2000). Saving to overcome borrowing constraints: implications for small business entry and exit, Small Business Economics, 15(3), p. 223.

Robb, A.M. (2002). Entrepreneurial performance by women and minorities: the case of new firms. Journal of Developmental Entrepreneurship, 7(4), pp. 383-397.

Russel, A. (2008). Poverty, not xenophobia, caused South Africa's explosion. Financial Times. May 24, pp. 9.

Shapero, A. (1975). The displaced uncomfortable entrepreneur. Psychology Today, 9(6), pp. 83-88.

Shapero, A. \& Sokol, L. (1982). The social dimensions of entrepreneurship. In C.A. Kent, D.L. Sexton and K.H. Vesper (eds.) Encyclopaedia of Entrepreneurship, pp. 72-90. Englewood Cliffs, NJ: PrenticeHall.

Smith, P.A. \& Metzger, M.R., 1998. The return to education: street vendors in Mexico. World Development, 26(2), pp. 289-296.

Teltscher, S. (1994). Small trade and the world economy: informal vendors in Quito,Equador. Economic Geography, 70(2), pp. 167-188.

Tissington, K. (2009). The Business of Survival: Informal Trading in Inner City Johannesburg. Centre for Applied Lega/ Studies (CALS). [On-line] Available: http://web.wits.ac.za/NR/rdonlyres/4376D73DE127-4C14-A579-1C61F681AF70/0/CALS_BusinessofSurvival_Dec09.pdf. (Accessed 11 January 2011)

Van Praag, M., De Wit, G. \& Bosma, N. (2005). Initial capital constraints hinder entrepreneurial venture performance. The Journal of Private Equity, 9(1), pp. 36-44. 